\title{
Research On The Influence Of Advertisement Positioning On Brand Shaping
}

\author{
Ya Xiao ${ }^{1, a}$, Fei Teng ${ }^{2, b}$ \\ ${ }^{1}$ Department of Media Art, Shijiazhuang Information Engineering Vocational College, Shijiazhuang \\ ,China \\ ${ }^{2}$ Department of Information Engineering, Tangshan Vocational \&Technical College, Tangshan, \\ China \\ a52772427@qq.com, bhuaihuai_1323@163.com
}

Keywords: Advertisement brand; Advertisement positioning; Brand shaping

\begin{abstract}
Advertising is an effective way of sales promotion. Proper advertisement positioning plays an important role in brand shaping and promotes the brand's value. At the same time, incorrect positioning will destroy brand image. Advertisement positioning theory and practice are investigated. And some elements influencing on brand shaping are analyzed.
\end{abstract}

\section{Introduction}

The modern advertising activity, often is based on the transfer of information. For the producers, advertising is a kind of channel for understanding the market dynamics and disseminating information to consumers. And for the consumers, advertising is an effective way to understand business information, the product performance and the operation status of the producers. As a tool, advertising has a lot of functions. But most businesses and manufacturers realize only the basic function that it promotes sales and increase the sales. There is no doubt that advertising can make a substantial increase in sales of products, the result is that every marketer and businesses and manufacturers are willing to see. However, the rise in product sales is not equal to the enterprise's products have been accepted by consumers, nor is the product brand value, so only the increase in sales of this result is not enough. Advertising is a double-edged sword, some advertising, the information is passed out, but the brand has come down. Advertising is not effective on behalf of all, consumer recognition of the brand and can not through advertising investment or increase in sales[1,2].

Under the background of fierce market competition,especially in the situation of more and more serious brand homogenization, brand has become an increasingly prominent role in brand marketing, and advertising has been an important means and method for shaping brand. With advertising, brand message can be effectively passed to consumers and enterprises can set up good images so as to establish a strong brand and gain the competitive advantage. We can see a lot of advertisements in our daily life. Some ads are easily accepted by consumers and works well,however, some other ads use celebrity effect and cost a lot, but the results are unsatisfactory. Considering the reasons, an important point is inaccurate position of advertising, which affects the establishment of advertising subject and whether the advertising effectiveness and branding are successful. Therefore, ad positioning is very important to brand shaping[3,4].

In the process of shaping the brand, advertising plays a role which can not be ignored. When the advertising promoting the sales of the products, how to make the advertising of the enterprises to enhance the brand value of the enterprise at the same time? That is to say how can we will advertising benefit truly precipitation for the economic efficiency of enterprises and where better to play advertising in promoting role in the process of brand value? This paper believes that a correct positioning of the advertising and is very necessary to strengthen the construction of the core value of brand[5,6]. 


\section{Advertisement Positioning And Its Theoretical Research}

The Theoretical Definition Of Ad Positioning.The founders of positioning theory Al Ries and Jack Trout ever pointed out that positioning is a concept,it has changed the nature of advertising. Positioning starts from products, for example a kind of goods or service, a company,an agency, even a person or maybe yourself. But positioning does not need you to do anything with the product. It needs you to make efforts in your future potential consumers, namely position the product in the minds of them. From the discourse of the advertising masters, it is not difficult to find out that positioning is an activity that the seller determines the targeted consumer group according to the market segmentation. The objective of ad positioning is to find the right and accurate location in the minds of these consumers. Therefore, ad positioning is a method for advertisers to help the enterprise or brand determine location in the consumers' minds through advertising activities[7].

The Theoretical Source Of Ad Positioning.The development of ad positioning theory has experienced four phases: USP stage, image advertising stage, ad positioning stage and system image ad positioning stage. The first phase: USP stage. In the 1950s, Rose Reiff J proposed that advertising should be unique. He advocated advertising should focus on product features and consumer interests. He emphasized that the difference among goods should be noted and we had better select characteristics easily accepted by consumers as the advertising theme. The second phase:image advertising stage. From 1950s, the homogeneity of products is more and more serious. Many advertisers use varieties of advertising and promotional tools to improve the reputation of enterprises and create famous brand products, which makes consumers select products according to the enterprises' reputation and images. The advertising ideas in this period focus on establishing brand images and promoting marketing activities in the objective advertising practice. The most representative person of this period is David Ogilvy, known as "architecture master of image stage". One of his most famous proposition is that every ad is the long-term investment for brand image. The third phase: ad positioning stage. "Positioning" began to be used in this period. From the generation in early 1970s to its peak in the mid 1980s, the core of advertising theory is making products set a place in the minds of consumers. Advertising entered an era dominated by positioning strategy when entering consumers' mind must be the first choice. The fourth phase: system image ad positioning stage[8]. Since 1990s, the world economy has increasingly broken regional boundaries and developed into the global economy. The competition among enterprises has changed from local product,price,information and consciousness competition into the whole corporate image competition. The original idea of ad positioning has developed into system image ad positioning. The thought determines ad positioning from the perspective of integrity,nature and and superiority, which changes the locality and subjectivity of product and enterprise image positioning.

\section{Some Problems Of Ad Positioning In Brand Shaping}

There are some really excellent ads with innovative ideas and accurate positioning, which play important roles in shaping good brand images. But at the same time, there are also some problems with other ad positioning bad for brand shaping, which are shown in Fig. 1.

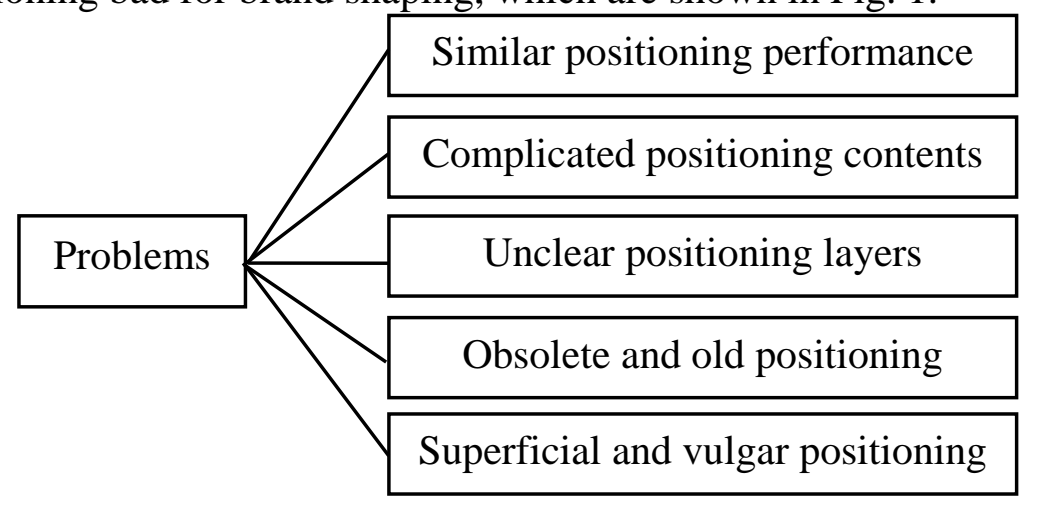

Fig. 1 The problems of ad positioning in brand shaping 
The Similar Positioning Performance.In the situation of buyers' market, the competition has become more and more fierce. The manufactures start operating when they find out a kind of product is profitable, such as "refrigerator war", “air conditioner war”, “TV war”,"VCD war” and so on. It leads to the increase of the same kind of products with slight differences in quality. This situation adds difficulties to the advertising originality and it's easy to be similar to others. For example, the recent advertisements of air conditioner mostly focus on healthy, green and environmental ideas. It uses imagery to make connection with green and healthy sense. The Green series advertising of Gree air conditioner is a typical representative,with which other advertisements about air conditioner have followed and the positioning and display mode are similar.

Complicated Positioning Contents.Some ads want to keep up with everything, but ad positioning is not a face but a point. If it displays everything, it will be lively and profound,or even offensive. For example, in today's popular TV shopping advertisements, the ads pack so many ingredients that they're unable to attract audiences to resonate. Therefore, it's very important to make ad positioning to the point[9].

Unclear Positioning Layers.Some ads are unclear about the points they want to highlight, or the positioning changes many times in a very short period. The American Bulumin Dai Charles Mall is famous for high-end prices, Kemat Mall is featured on sale, the two malls play their proper roles. However Sears Mall located between the above two malls once fell into poor management because it wanted to imitate Kemat Store on sale. As a result,the sale of luxury goods was affected and the mall suffered a heavy loss for its confused ad positioning and fuzzy image.

Obsolete And Old PositioningIn a sense, the essence of brand innovation is to curb brand aging. Here are a lot of ways to make brand rejuvenation whose key lies in the ad positioning of innovative concept and brand promotion. Obsolete and old ad positioning is not conducive to long-term development of brand. For example, Nongfu spring ever took the activity of donating a penny to bid for the Olympic Games as the ad positioning for promotion. It really won a success. Now the same idea is copied to the children that we donate money for their hopes.Ad positioning can't stay on one level to play word games. It's better to make a deep digging.

Superficial And Vulgar Positioning.It has become common phenomenon in advertising without combination. It doesn't refer to the media here, but the depth of digging about brand ad positioning. It's easy to see there is almost only one ad positioning whether in new brand's market or in ripe brand's one. For example, the reason for Melatonin advertising's winning first place for many years is that it patiently warns people across the country that "If you send gifts, select Melatonin". In the ad,a group of old men and women beat gongs and sound drums to boast Melatonin effects, even with the use of news. This kind of superficial ad doesn't consider the feeling of audience but it's played over and over again and makes "Don't receive gifts this festival except Melatonin” known across the country. Of course people are really bored with it. The superficial and vulgar ads don't have any benefit to brand value promotion but play negative roles.

\section{The Key To Brand Shaping From Ad Positioning}

The key to brand shaping from Ad positioning includes three aspects which are shown in Fig.2.

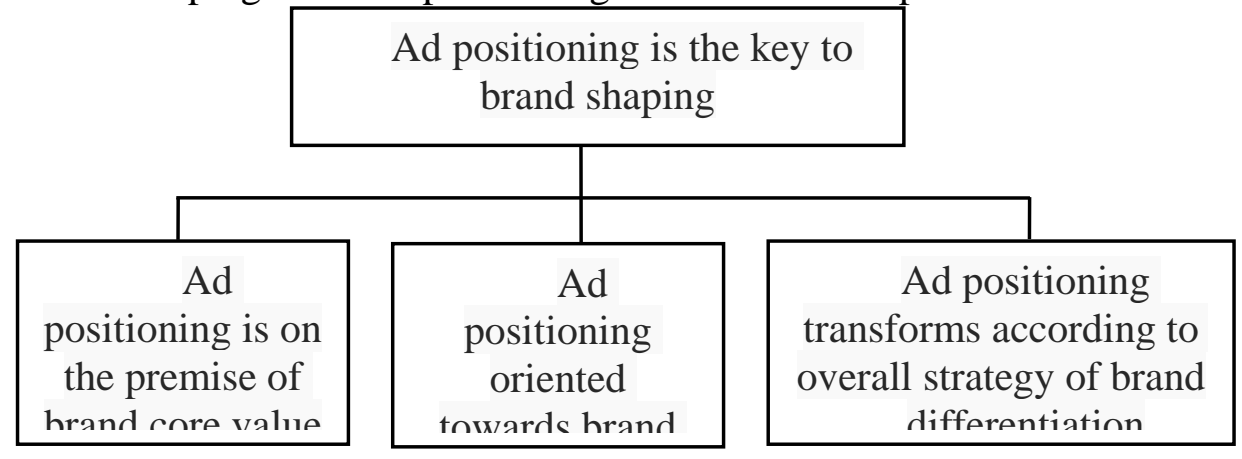

Fig.2 The key to brand shaping from Ad positioning 
Ad Positioning Is On The Premise Of Brand Core Value.Ad positioning is the premise and basis of successful advertising. Without successful positioning, ads will not have a lasting effect and play roles in enhancing the enterprise's image and brand value. But the accurate positioning of advertisements is a necessary but not sufficient condition to enhance brand value. As a result, ad positioning can effectively promote brand establishment and brand value on the premise of core value of the brand. If the brand itself doesn't have the core value or correct brand awareness, or the ad positioning doesn't focus on the brand, the effect of promoting brand value can't be achieved and the advertising effect can't be settled for intangible asset.

Joison Consulting Company in Shanghai ever made a research on brand equity of five Chinese TV brands in the form of seminar survey in six cities. In this study, Joison allowed consumers to make association on every brand with no limit. Results showed that there were basically no difference among brands. For example, the ad positioning of distilled spirit digs out brand identity and value almost from the perspective of long history,good luck, happiness and forthrightness. The core value without much difference means giving up loyal customers.

Ad Positioning Oriented Towards Brand Differentiation.Ad positioning of brand differentiation is that enterprise consciously forms a positioning strategy separated from competitive brands by establishing functional and emotional differences. In fact, there are differences among any brands, which are formed with natural factors or human factors. Ad positioning of brand differentiation can not only avoid the negative impact that differences have on brands, but also strengthen the positive promotion of brands caused by differences through brand recognition. The core value of brands is mainly expressed in three aspects:the function of the brand value, the emotion of the brand value and self-expression of the brand value. To be successful in shaping brand and enhance the brand value is the objective of forming differentiated ad positioning. Therefore, the formation of differentiation of brand ad positioning should be oriented to the brand differentiation from the perspective of the function, emotion and self-expression of the brand value[10].

Five famous shampoo ads of P\&G are shown in Fig. 3.

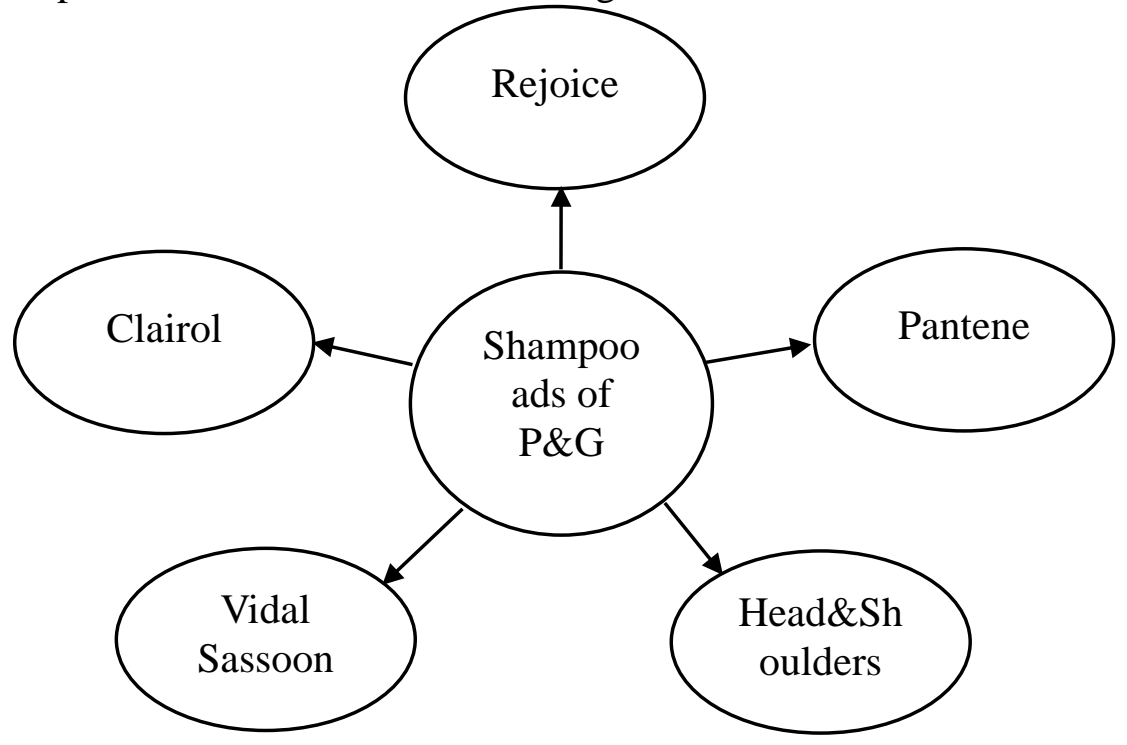

Fig.3 Five famous shampoo ads of $P \& G$

Almost everyone is familiar with these five brands whose market share is amazing. P\&G occupies half of the shampoo market relying on brand concept and accurate positioning of the ads. The company uses ad positioning oriented towards brand differentiation to gain the status recognized by consumers thereby to lead the shampoo market. For example the ad positioning of Rejoice is smoothness and confidence. Its characteristic conveys the concept of "smoothness". Then the ad focuses on "self-confidence", "To be confident because of smooth hair", "Women who use Rejoice are more confident." The ads try to introduce the concept of "confidence" into the minds of consumers. The advertising can both meet the interests and emotional appeal. The ad positioning of 
Pantene is nutrition and health. The selling points such as "nutrition and health", "Flash health glow." and "Luster in strong characteristics" are rooted among the people. The ad positioning of Head\&Shoulders focuses on anti-dandruff. The advertising conveys the main idea that "No dandruff makes us close". The advertisement is "Dandruff disappears, the hair is superior". Head\&Shoulders makes a bi-directional positioning that reminds consumers of it when they think of "dandruff" and the opposite situation. The advertisement of Vidal Sassoon follows the route of professional hair salon whose colors are mainly red and black with the recommendation of professional hair stylists so that it gives people the feeling of authority. "Inspired by the Vidal Sassoon Academy", "Vidal Sassoon shows personal style.” At the end of advertising reflect the professional of Vidal Sassoon and have a unique style. The ad positioning of Clairol is herbal essence and aroma. The natural temptation is the main selling point of it. Most ads of Clairol have a close contact with nature, trying to render the herb's nature strength. Its intense aroma is enough to refresh spirits and win considerable fixed consumers that makes the potential market tend to be more younger.

Ad Positioning Transforms According To Overall Strategy Of Brand. Overall strategy of brand establishes guidelines and basic principles which starts with brand construction and management. It promotes brand construction to the height of management strategy with the goal of establishing strong brands and creating brand value. A strong band itself meets several basic requirements of core competitiveness of enterprises, namely precious,unique and can't be copied and hard to replace. Coca Cola is a typical example. The president with tens of billions of dollars says: Even if a fire burns all the factories around the world, it can come back to life relying on the brand.

Because there are some adverse factors for brand shaping such as dislocation, out-of-date, limited market attraction and lack of advanced nature of ad positioning, it needs transformation, which should be based on the overall brand strategy, so as to establish a lasting competitive brand.

\section{Conclusions}

Brand shaping is a systematic project that needs to strengthen its internal practice. It's undeniable that advertising plays an important role in shaping brands,especially successful ad positioning affects the success of brand shaping. In a word,ad positioning and brand shaping have a special relationship. Ad positioning is the premise and basis of successful advertising. Without accurate positioning, ads won't have a lasting effect and play the role of shaping and enhancing brand value. If ads don't have unique positioning and enough personality,information passed by brands may be weakened,even drowning. Therefore only right ad positioning can make the message sent by ads different from them of other brands and stand out from the numerous advertising and then accepted by the consumers and affect their spending orientation and purchasing behaviors.

\section{References}

[1] Susan M. Sherman, Hannah Follows, Alexander B.R. Mushore, Kathleen Hampson-Jones, Katie Wright-Bevans. Television advertisements create false memories for competitor brands. Journal of Applied Research in Memory and Cognition. Vol. 4 (2015), p. 1-7.

[2] Ufuoma Akpojivi, Ayesha Bevan-Dye. Mobile advertisements and information privacy perception amongst South African Generation Y students. Telematics and Informatics. Vol. 32 (2015), p. 1-10.

[3] Wiebke Schulz, Ineke Maas, Marco H.D. van Leeuwen. Employer's choice - Selection through job advertisements in the nineteenth and twentieth centuries. Research in Social Stratification and Mobility. Vol. 36 (2014), p. 49-68.

[4] J. Sridevi. Effectiveness of Celebrity Advertisement on Select FMCG - An Empirical Study. Procedia Economics and Finance. Vol. 11 (2014), p. 276-288.

[5] Mutlu Er. The Active Role of the Recipient in Decoding an Advertisement Respectively a Poster. 
Procedia - Social and Behavioral Sciences. Vol. 70 (2013), p. 52-60.

[6] Marika Tiggemann, Amy Slater, Belinda Bury, Kimberley Hawkins, Bonny Firth. Disclaimer labels on fashion magazine advertisements: Effects on social comparison and body dissatisfaction. Body Image. Vol. 10 (2013), p. 45-53.

[7] Jana Möller, Steffen Herm. Shaping Retail Brand Personality Perceptions by Bodily Experiences. Journal of Retailing. Vol. 89 (2013), p. 438-446.

[8] Nina Michaelidou, Milena Micevski, John W. Cadogan. An evaluation of nonprofit brand image: Towards a better conceptualization and measurement. Journal of Business Research. Vol. 68 (2015), p. 1657-1666.

[9] Albert A. Barreda, Anil Bilgihan, Khaldoon Nusair, Fevzi Okumus. Generating brand awareness in Online Social Networks. Computers in Human Behavior. Vol. 50 (2015), p. 600-609.

[10] Mar Gómez, Carmen Lopez, Arturo Molina. A model of tourism destination brand equity: The case of wine tourism destinations in Spain. Tourism Management. Vol. 51 (2015), p. 210-222. 